\title{
Design and Implementation of English for Academic Purpose Online Learning System Based on Browser/Server Framework
}

\author{
https://doi.org/10.3991/ijet.v13i03.8399 \\ Yan Gong \\ Baoji University of Arts and Sciences, Baoji, China \\ gongyan1100@163.com
}

\begin{abstract}
Today, with the rapid development of the information age, the education reform tends to be internationalized. The tertiary-level EFL education in colleges and universities has also changed its original model with focuses on cultivating general-purpose linguistic skills to one on students' English for Academic Purpose (EAP). EAP English instruction has been vigorously popularized in research-based universities. To achieve the informationized and standardized management for EAP English instruction work in the universities, in this paper, we design and develop a EAP English online learning system with B / $\mathrm{S}$ as the system development framework by which the system's overall functions are designed. MySQL is chosen as a database development tool used to implement the main object module, while JSP technology is used to support the cross-platform mechanism in order to access to diversified data sources. It is proved by the test on system operation that this system features operability, easy to use and maintain, and enables to meet the needs of university students for EAP English learning and teaching management, improves the students' EAP English learning model and efficiency.
\end{abstract}

Keywords - B/S structure, JSP technology, MySQL, EAP English, online learning

\section{Introduction}

Today, with the rapid development of information technology in the world, China has witnessed the ever-increasing internationalization in politics, economy and culture education. For the purpose of talent cultivation, the country and society show more concern about whether students in research-based universities can directly read professional literature and write academic papers in English, attend the international academic conference for academic exchanges, or study abroad [1,2]. In the past, EFL education simply focused on the cultivation of general-purpose linguistic skills, ignoring the students' EAP language competence. For this reason, the universities have generally carried out the reform on the EFL education, that is, transformed it from the language-based general English into academic English for professional learning service, namely EAP [3]. In order to face the tide of reform and achieve the information- 
alized and standardized management of college EAP English instruction, it is of great practical value to design and develop EAP English online learning system in colleges and universities.

\section{Basic theory for system design}

\subsection{B/S model architecture}

B / S (Browser/Server) structure is improved based on C / S structure. This architecture supports the working interfaces implemented by the browser [5,7]. On the front end, there are less business logics, because most of them concentrates on the server side. This greatly lightens client computer, and reduces system maintenance, upgrading and other costs and the workloads since there is almost no need to maintain the client. Currently, the B / S architecture can be used to develop the software at a stroke, and allow different people to access and operate the same database from anywhere by various modes $[8,9,10]$. It effectively manages access rights, and guarantees the security of data platform and server database.

\subsection{JSP development language}

JSP (Java Server Pages), as the technology standard for active Web pages, allows Web server receive the requests to access JSP pages, return the HTML code and result to the user after executing the program segment. This technology is developed based on JavaServlet, since the smooth development of large-scale programs often requires an integration between JavaServlet and Java $[11,12,13]$. JSP is analogous to JavaServlet. Both of them are executed in the server but return the HTML text to the client, where you can browse it simply by a browser installed thereon. In relation to other relevant technologies, JSP technology enables a faster learning rate, and is relatively simple, with which the program can run everywhere after being written once; it features transferability, reusability, cross-platform, etc.; the Java program therein allows access to most of the database systems, and has the advantages of database links.

\subsection{Mysql Database}

MySQL is a robust, multi-user, multithreaded SQL database service management system. It supports the heavy-loaded production systems and some key services, and can also be inlaid in the huge capacity software. The system is written in $\mathrm{C}$ and $\mathrm{C}++$ and tested with many compilers in order to ensure that the source code is portable. It supports a lot of operating systems including AIX; provides API for many programming languages; fully allows multiple threads in parallel and enables to use CPU resources; and besides, it also enables a faster query by using optimized SQL query algorithms $[14,15]$; it provides a number of database links, specifically involving ODBC and other paths; for the management of database operations, the improved 
management tools are also provided; the large databases can be available for dealing with mass data.

\section{$3 \quad$ Requirements Analysis of EAP English Online Learning System}

\subsection{Implementation objective}

The purposes of developing this system are as follows: to transform more complex EAP management, English learning activities into the informationalized operations, more definitely and specifically; to complete the instruction management in combination with the learning process, effect; to direct students to accomplish the tasks while allowing them to timely answer the questions in order to carry out the information management for learning and teaching processes. The system specifically involves the following relevant functions, such as student learning, teachers, administrators, communication, management for test activities, and takes teachers, students, administrators as a specific business objects.

\subsection{Business analysis}

The Business Process Analysis (BPA) in the system can define some basic elements such as cooperation modeling and process work, and better analyze and recognize the relationship of it with relevant elements. In the requirement analysis for the system focuses on EAP English instruction, learning business process. The following is a simple analysis for the system's business processes.

Admin business analysis. Admin business process: they can access to background management modules and maintain the information of itself; query the information about teachers, as well as their classes, or add and delete such maintenance and management works. it also allows to assign appropriate classes for teachers.

Teacher business analysis. Teacher business process: they can smoothly access to the system, and maintain personal profiles, also access to management modules; enable to query the students' EAP learning progress, dictionary content, and manage them; publish EAP English writing, comprehensive tests; inquire the test scores. Besides, teachers can also manage forum posts.

Student business analysis. Student business process: they need to successfully log in the system, and thus can maintain their own information; access to test pages, learning tasks, etc.; exchange experience by posts, replies, etc.; access to the learning pages where they can query learning notes, schedules, etc.; access the test interface where they can have writing, comprehensive tests; after the test, they can view the results; log in the forum, and also perform some operations such as replies, posts, etc..

\subsection{System case analysis}

Admin case analysis. The specific functions in this part are given as follows: 
Administrator: Add or delete teachers, classes, etc., correctly modify the teacher information, query the class information.

Database: read and write data accurately, and in a relatively safe manner.

Precondition: the administrator can successfully skip to the login screen, teacher management interface, etc.

Postcondition: return to the list of teachers.

Teacher case analysis. The specific functions in this part are given as follows:

Teacher: view the class information, query the learning schedule, edit the test paper library, that is to say, extract a number of papers from the test paper library in order to facilitate students to randomly make a selection for examination, check the test paper, delete, reply and send posts.

Database: read and write data accurately, and in a relatively safe manner.

Precondition: teachers need to successfully $\log$ in the system, and go to the main interface.

Post-conditions: After successfully entering the system, skip to the success page, and return to the main interface; access the lists of the subjects and the student logins, and return to the lists of posts, dictionaries and so on.

Student case analysis. The student subsystem case analysis is shown in Fig.1:

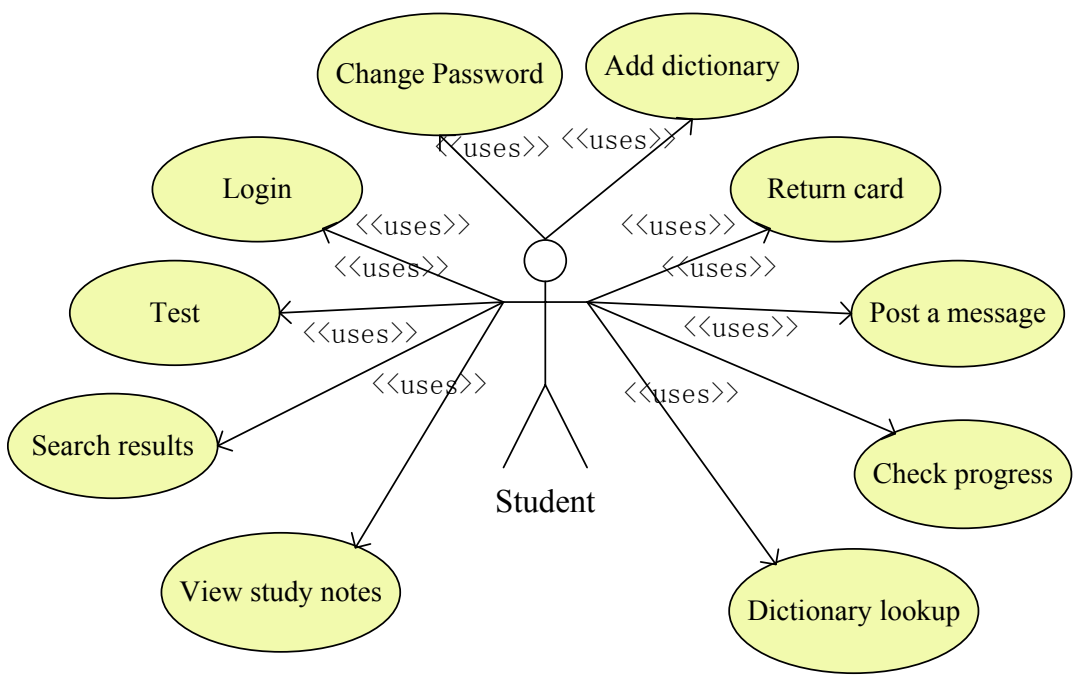

Fig. 1. Student use case diagram

This part includes several specific functions as follows:

Students: complete the exams, and query the results, view the learning schedule, finish the inquires, add new fields, reply and send posts and other functions.

Database: read and write data accurately, and in a relatively safe manner.

Preconditions: smoothly enter the system, skip to the home page, access the list of students' test papers, the learning worlds and many other interfaces.

Postconditions: return the student papers, results, the list of dictionaries, the learning worlds and the students' home pages. 


\subsection{Modelling for primary business behaviors}

As far as the system R \& D programs are concerned, the following business behaviors are relevant, such as teachers can view the specific learning schedules of students, and are responsible for reviewing the forum posts sent by students, teachers make out the test papers required to be answered by students.

Business modelling for making out test papers. After entering the test paper library, the teachers randomly extract the test papers and sends them to the system; after entering the test interface, whether students choose the test or not, if the answer is Yes, the papers should be finished and submitted. After that, the process is ended up; teachers receive, archive the students' results to complete their process. The business process is shown in Fig. 2.

Business modelling for learning schedule. Teachers need to arrange and send the learning tasks for students. After receiving this, students can be allowed to complete the tasks on schedule. After the tasks are completed, students can determine whether to continue this process, if so, the system reads the schedule of previous tasks and updates it after they are finished, in order to make feedback to the teachers; if not, the system will resume the schedule and return it to the teachers after initialization. The appropriate timing sequence is shown in Fig. 3:

Business modelling for new dictionaries. Teachers deliver the dictionary to students for an update. The system skips to appropriate interface after students accept it, and sent it to the teachers after the new words are entered for the teacher to review them. If they match the requirements exactly, they save and archive the new words, so that the process is ended up; otherwise, they store them, and inform the students of unconformity. The process is then over.

Business modelling for replies and posts. Replies, posts and other functions appear in the forums. As a system members, teachers and students $\log$ in the forum. If they fail to login, then return to the home page; if successfully, skip to the forum, where you can browse the corresponding posts, then reply or publish the posts and perform other operations.

\subsection{Function Requirements Analysis}

Function requirements refer to all of the functionalities that the target software system must accomplish, which must be eventually defined in the requirements analysis phase by collecting the needs of users for software. The system designs and implements several major functions, including:

Information management. It includes the authority management, such as personal profile maintenance, information inquiry, modification and deletion.

Learning management. It refers to teachers' supervision and management for learning process of students, such as publishing learning tasks, inquiring students' learning schedules, notes, results and times, approving students' newly updated dictionaries, etc.. 
Online test. It means that students participate in online exams and query their scores, such as comprehensive test and writing assessment, and then query their own relevant results.

Communication and interaction. It refers to such process that the teachers answer questions raised by students, such as posts and replies between teachers and students, teachers query the posts, reply and delete those.

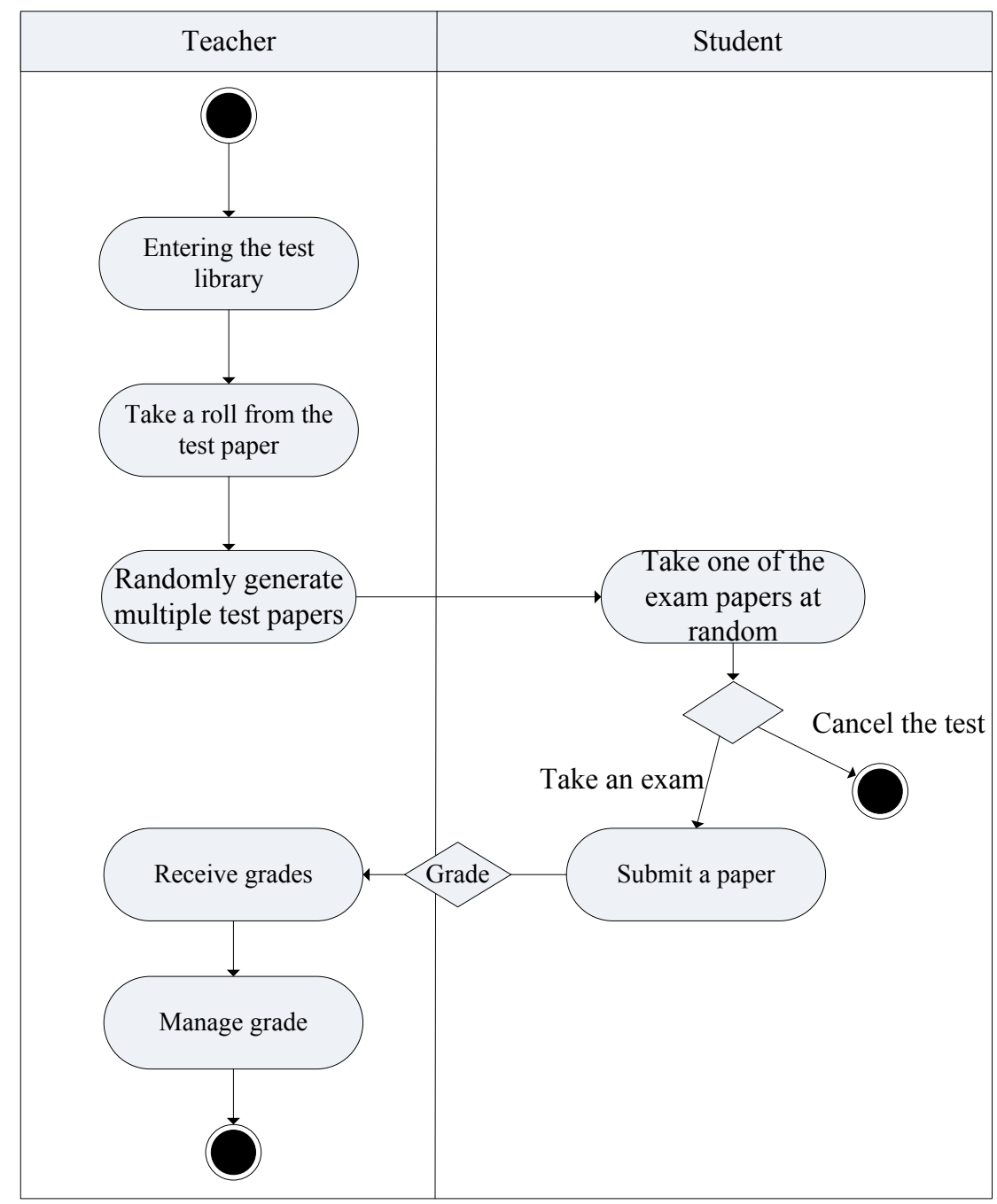

Fig. 2. An activity chart for the volume test 


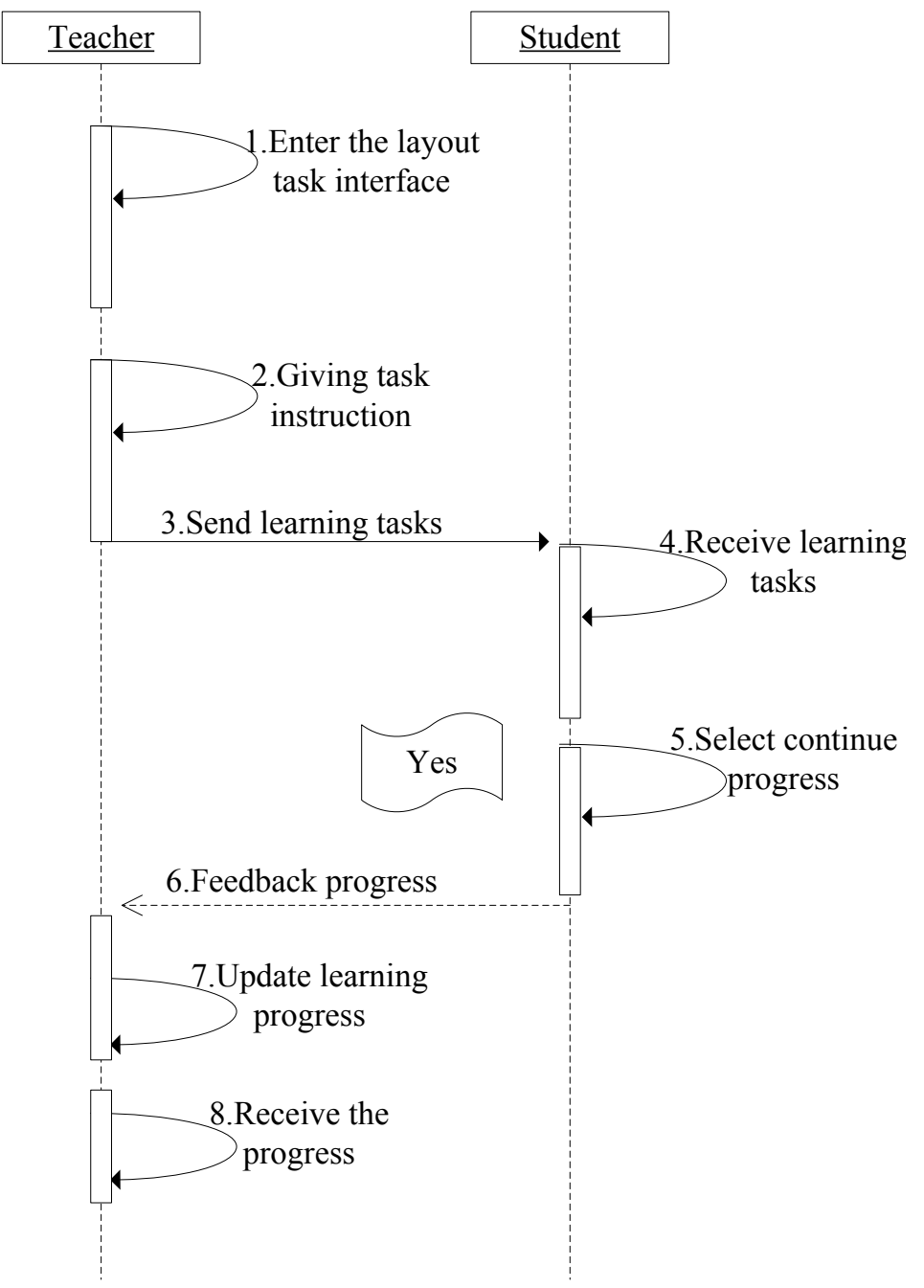

Fig. 3. View the learning progress sequence diagram

\section{Design of EAP English Online Learning System}

\subsection{System Network Architecture}

The system network architecture is shown in Fig. 4. Server is connected with switches. The routers and firewalls are used to access the external networks and campus networks; the switches are also connected to computers and other devices in the dormitories and teaching building to form a network architecture. The system is more applied in the internal network, which not only achieves a relatively low load and a high security, but also ensures execution efficiency and rate. 


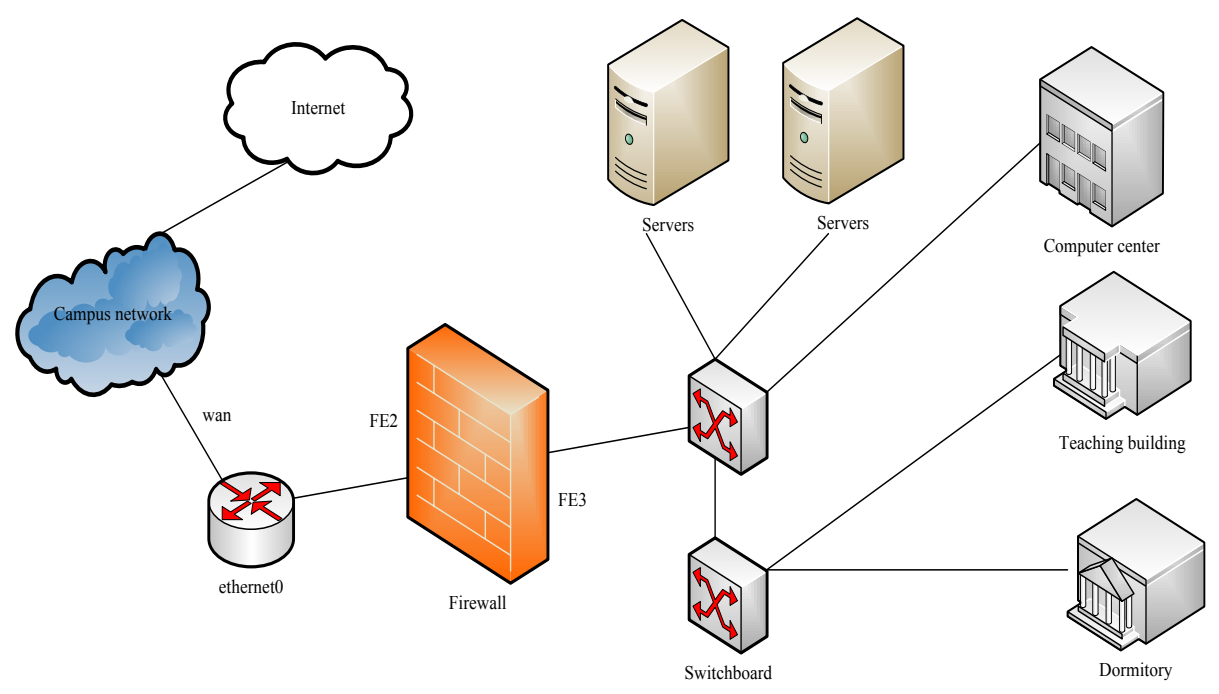

Fig. 4. Architecture diagram of EAP English online learning system

\subsection{Overall functions}

A variety of user objects are incorporated to divide the system into three major modules, i.e. teachers, administrator and students. After the administrator successfully logs in the system, he or she can manage the teachers, classes and personal profiles; after the teachers successfully logs in the system, they can manage learning status, posts, students, personal profiles and test status; as student users, they register according to classes in the system. After they successfully enter the system, they can perform a series of operations, including manage their own information, apply the dictionaries, check the schedules, complete the tasks, participate in the tests, and query the results, and also reply the posts in the forum, send the posts. For the system, the overall function module design is shown in Fig.5.

\subsection{DB design}

Conceptual Model. The relational database system often combines E-R diagram to analyze the data structure, which mainly involves three major parts, that is, relations, attributes and entities. In this system, the design attributes, entities can be found in Fig.6.

Design of datasheet. By combination with the physical model, the multiple entity sheets can be designed, together with business requirements, so can the corresponding storage view and process.

The system must design 17 sheets, including a list of student notebooks, the teacher information list, a list of examined test papers, and the dictionary table, etc. The following is the dictionary table: 


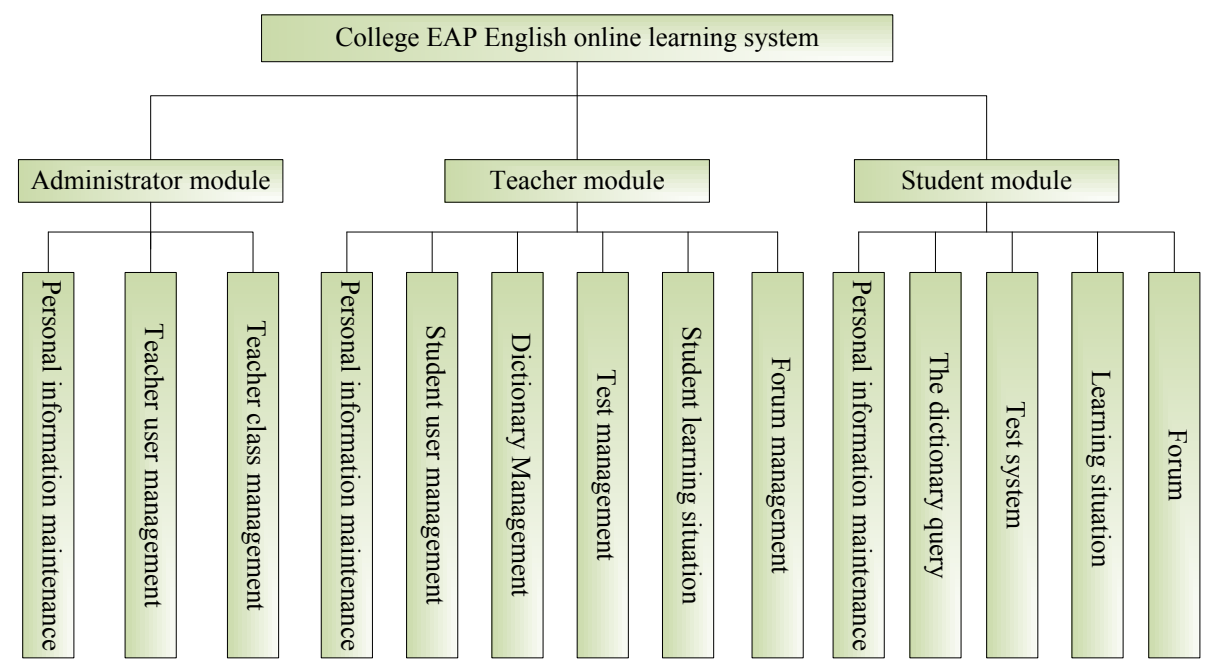

Fig. 5. College EAP English online learning system

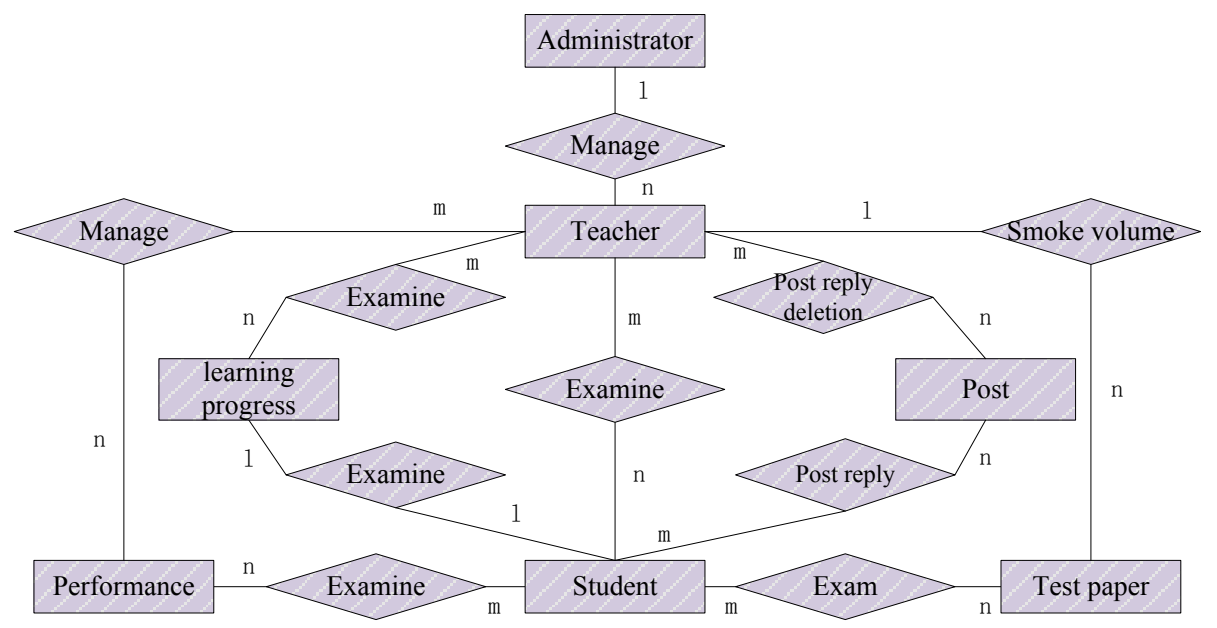

Fig. 6. Main entity relationship diagram

Table 1. Dictionary table

\begin{tabular}{|c|c|c|c|c|c|c|}
\hline Table name & \multicolumn{2}{|c|}{ Dictionary table } & English name & \multicolumn{2}{c|}{ Translate } \\
\hline Major key & \multicolumn{2}{|c|}{ English } & Foreign key & & \\
\hline Order & Name & Type & Size & $\begin{array}{c}\text { Required } \\
\text { Field }\end{array}$ & Default & Remark \\
\hline 1 & English & char & 255 & $\sqrt{ }$ & & Note in English \\
\hline 2 & Chinese & varchar & 32000 & $\sqrt{ }$ & & Chinese meaning \\
\hline
\end{tabular}




\subsection{Object modelling}

The system object-oriented modeling classes are shown in Fig. 7: the quadrilateral is used to represent the class, where the attributes, the class names and the appropriate operation modes are involved. The arrow on left side is the relationship between the classes; the quadrilateral on right side corresponds to the method of the class on the left side. The classes on right side all have their respective unique methods. As shown in the figure below, we can learn that three classes on the left, including students, administrator and teachers, are provided. On the right there are dictionaries, replies, test papers, etc. The students and the teachers correspond to all the methods on the right.

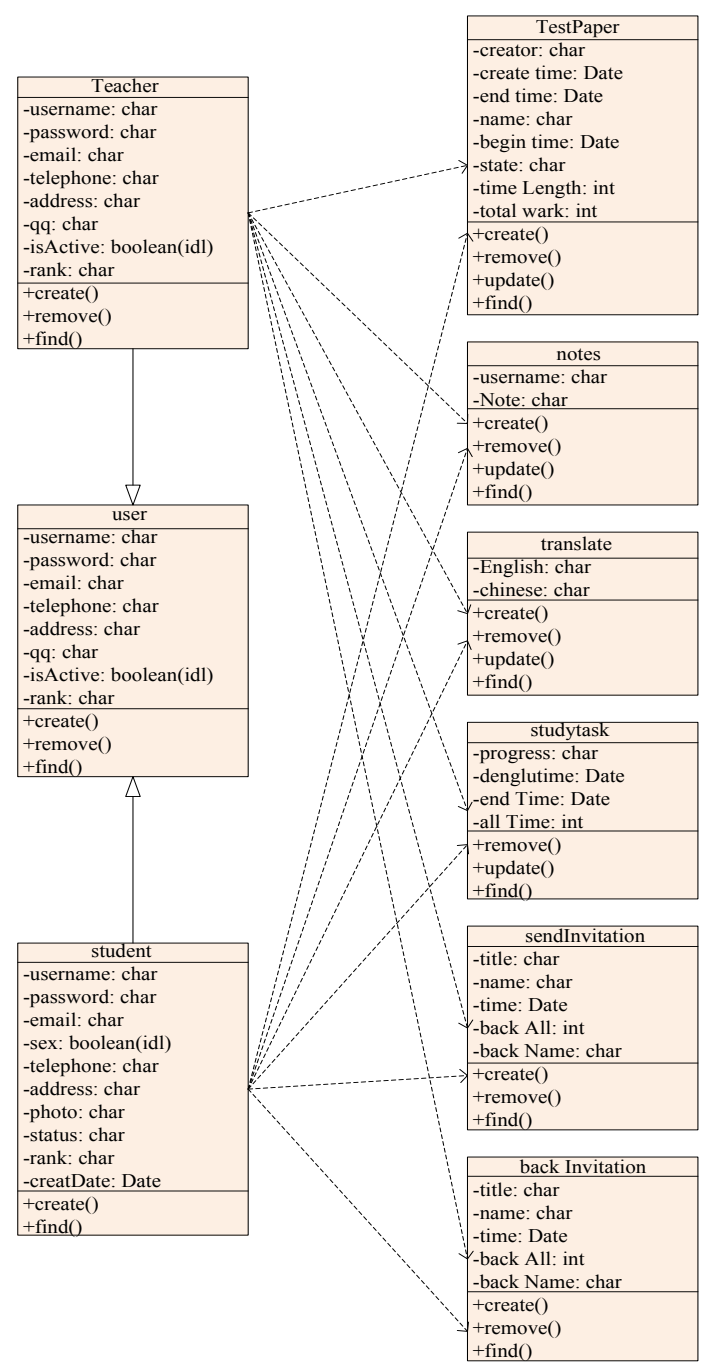

Fig. 7. Class diagram of EAP English online learning system 


\section{$5 \quad$ Interface design}

System interface is designed with the following types of functions embedded: student activities, teachers, administrator manager and login interface. For the login interface, after the registration operation is done, the user inputs the account information in it to $\log$ in the system, see Fig. 8 for details.

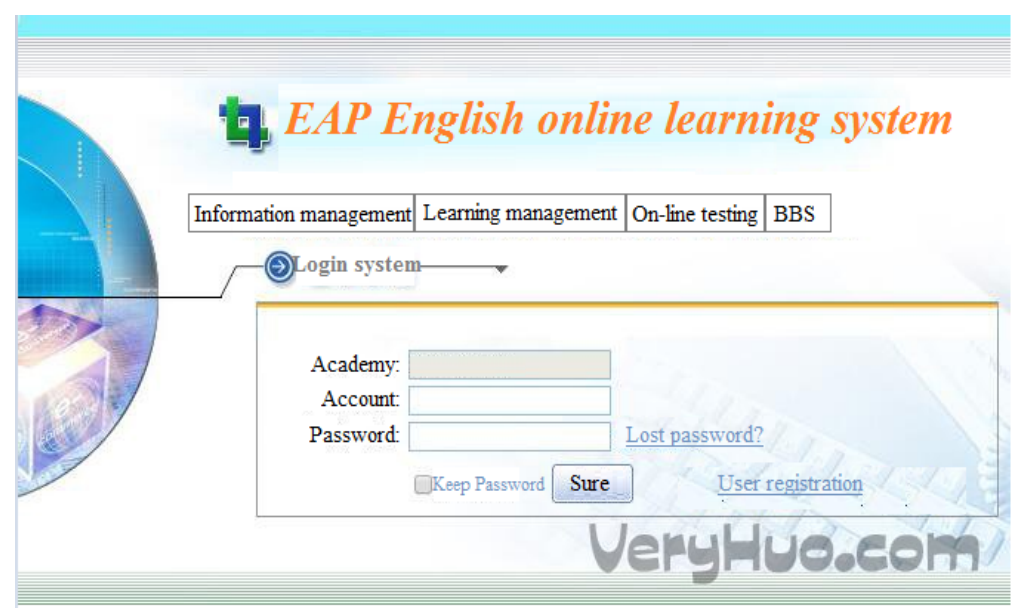

Fig. 8. EAP English online learning system login interface chart

\section{Conclusion}

1. In this paper, we design and develop the college EAP English online learning system with overall functions designed on B / S system development framework.

2. MySQL is chosen as a database development tool to design logical structure and sheet structure of the database, while the object modelling is performed.

3. JSP is used to support cross-platform mechanism in order to access different data sources, thus achieving information sharing and cross-platform access to information resources.

4. It is proved by the system running test that the system is simple, easy to use and maintain, and will be able to meet the needs of colleges and universities for EAP English learning and teaching management, greatly improve the EAP English learning model and efficiency of students.

\section{$7 \quad$ Acknowledgment}

Planning projects of Shaanxi educational science "the $13^{\text {th }}$ Five-Year Plan" (SGH17H268); Key research projects in Baoji University of Arts and Sciences (ZK16081); Scientific research projects of the $11^{\text {th }}$ education reform in Baoji University of Arts and Sciences (JGYB15043). 
Paper-Design and Implementation of English for Academic Purpose Online Learning System Based ...

\section{References}

[1] Arnó-Macià, E., Rueda-Ramos, C. (2011). Promoting reflection on science, technology, and society among engineering students through an eap online learning environment. Journal of English for Academic Purposes, 10(1), 19-31. https://doi.org/10.1016/j.jeap.20 10.12 .004

[2] Asoodar, M., Atai, M. R., Vaezi, S., Marandi, S. S. (2014). Examining effectiveness of communities of practice in online english for academic purposes (eap) assessment in virtual classes. Computers \& Education, 70(C), 291-300. https://doi.org/10.1016/j.compedu.20 13.08.016

[3] Allison, D. (2004). Creativity, students' academic writing, and eap: exploring comments on writing in an english language degree programme. Journal of English for Academic Purposes, 3(3), 191-209 https://doi.org/10.1016/j.jeap.2003.11.005

[4] Tribble, C. (2015). Writing academic english further along the road. what is happening now in eap writing instruction. Elt Journal, 69(4), 442-462. https://doi.org/10.1093/ elt/ccv044

[5] Green, J. H. (2015). Teaching for transfer in eap: hugging and bridging revisited. English for Specific Purposes, 37, 1-12. https://doi.org/10.1016/j.esp.2014.06.003

[6] Qingli, Zhao. (2013). Design and application of english learning system based on b/s structure. International Journal of Technology Management, 97-99. https://doi.org/10.2495/ GCN131132

[7] Campion, G. C. (2016). 'the learning never ends': exploring teachers' views on the transition from general english to eap. Journal of English for Academic Purposes, 23, 59-70. https://doi.org/10.1016/j.jeap.2016.06.003

[8] Mcintosh, K., Connor, U., \& Gokpinar-Shelton, E. (2017). What intercultural rhetoric can bring to eap/esp writing studies in an english as a lingua franca world. Journal of English for Academic Purposes, 29, 12-20. https://doi.org/10.1016/j.jeap.2017.09.001

[9] Dashtestani, R. (2013). Iranian english for academic purposes (eap) stakeholders' attitudes toward using the internet in eap courses for civil engineering students: promises and challenges. Computer Assisted Language Learning, 26(1), 21-38. https://doi.org/10.1080/ 09588221.2011 .627872

[10] Mcdonald, A. G., Boyce, S., Moss, G. P., Dixon, H. B., Tipton, K. F. (2007). Explorenz: a mysql database of the iubmb enzyme nomenclature. Bmc Biochemistry, 8(1), 14. https://doi.org/10.1186/1471-2091-8-14

[11] Barron, C. (2003). Problem-solving and eap: themes and issues in a collaborative teaching venture. English for Specific Purposes, 22(3), 297-314. https://doi.org/10.1016/S08894906(02)00016-9

[12] Hyland, K. (1994). Hedging in academic writing and eap textbooks. English for Specific Purposes, 13(3), 239-256. https://doi.org/10.1016/0889-4906(94)90004-3

[13] Clark, D. B., Sampson, V., Weinberger, A., \& Erkens, G. (2007). Analytic frameworks for assessing dialogic argumentation in online learning environments. Educational Psychology Review, 19(3), 343-374. https://doi.org/10.1007/s10648-007-9050-7

[14] Shin, N., Chan, J. K. Y. (2004). Direct and indirect effects of online learning on distance education. British Journal of Educational Technology, 35(3), 275-288. https://doi.org/10.1111/j.0007-1013.2004.00389.x

[15] Sockett, G., Toffoli, D. (2012). Beyond learner autonomy: a dynamic systems view of the informal learning of english in virtual online communities. Recall, 24(2), 138-151. https://doi.org/10.1017/S0958344012000031 
Paper-Design and Implementation of English for Academic Purpose Online Learning System Based ...

\section{Author}

Gong Yan, born in 1981, Master of Arts; Engaged in the study fields: English language teaching and translation. Address: Baoji University of Arts and Sciences, No. 44, Xibao Road, Baoji, Shaanxi

Article submitted 07 February 2018. Final acceptance 23 February 2018. Final version published as submitted by the author. 